\title{
RELAÇÃO ENTRE A PRÁTICA DE ATIVIDADE FÍSICA, COMPOSIÇÃO CORPORAL E FATORES DE RISCO EM ADOLESCENTES OBESOS
}

\author{
Julia Loureiro Sion*, Silene Montoro, Mariana Simões, Roberto Teixeira Mendes
}

\section{Resumo}

O trabalho avaliou indivíduos pré púberes, púberes e pós púberes que acompanham no Ambulatório de Obesidade Infantil do HC-UNICAMP, em relação à seu grau de atividade física, seus níveis de massa óssea e de marcadores inflamatórios, que podem indicar os fatores de risco para doenças crônicas no futuro. Assim, estamos avaliando se há uma relação entre as causa dessa obesidade precoce, como o sedentarismo e a inatividade física com alterações nesses fatores de risco.

\section{Palavras-chave}

Obesidade, atividade física, marcadores inflamatórios

\section{Introdução}

A obesidade é uma condição clínica multifatorial caracterizada por acúmulo de tecido gorduroso localizado ou generalizado, provocado por desequilíbrio nutricional associado ou não a distúrbios genéticos ou endocrinometabólicos. Essa condição aumenta consideravelmente o risco de morbidade não só por Hipertensão Arterial Sistêmica (HAS), dislipidemia, Diabetes Mellitus tipo 2 (DM 2), Doença arterial coronariana, infarto agudo do miocárdio, osteoartrite e apneia obstrutiva do sono e problemas respiratórios, mas também por Cânceres de endométrio, mama, próstata e cólon. Na infância, a obesidade também leva ao surgimento de fatores de risco para essas comorbidades, apesar de algumas delas só começarem a se manifestar décadas mais tarde. Em relação às causas dessa obesidade precoce, os mais fáceis de serem modificados são o sedentarismo e a inatividade física. Entretanto, ainda não está bem documentado na literatura se há uma relação entre a prática de atividades físicas e possíveis mudanças nos fatores de risco para obesidade, nessa faixa etária ainda em desenvolvimento, sendo esse o objetivo do projeto.

\section{Resultados e Discussão}

Os dados dos pacientes já foram colhidos de seus prontuários, junto ao SAME do HC UNICAMP. As analises dos dados, assim como os resultados, discussões e conclusões ainda estão sendo finalizados e serão entregues no relatório final do trabalho, até o dia 8 de agosto de 2016. Nessa data, atualizarei o resumo e este arquivo com o texto e com tabelas e gráficos. Também serão apresentados no Congresso.

\section{Conclusões}

Os dados dos pacientes já foram colhidos de seus prontuários, junto ao SAME do HC UNICAMP. As analises dos dados, assim como os resultados, discussões e conclusões ainda estão sendo finalizados e serão entregues no relatório final do trabalho, até o dia 8 de agosto de 2016. Nessa data, atualizarei o resumo e este arquivo com o texto e com tabelas e gráficos. Também serão apresentados no Congresso.

1. Fisberg M. Obesidade na infância e adolescência. In: Fisberg M, ed. Obesidade na infância e adolescência. São Paulo: Fundação BYK;1995. p.9-13.

2. Steinberger J. Diagnosis of metabolic syndrome in children. CurrOpLipidol2003;14:555-9.

3. Neumark-Sztainer D, Story M, Hannan PJ, Perry CL, Irving LM Weight-related concerns and behaviors among overweight and nonoverweight adolescents: implications for preventing weightrelated disorders. ArchPediatrAdolesc Med2002;156:171-

4. Berkey CS, Rockett HR, Field AE, Gillman MW, Frazier AL, Camargo CA Jr, et al. Activity, dietary intake, and weight changes in a longitudinal study of preadolescent and adolescent boys and girls. Pediatrics2000;105(4):E56.

Atenção: $O$ arquivo não poderá ultrapassar 1 página. 